\title{
SIPP: Schedule-induced pellet pouching in the golden hamster
}

\author{
TIMOTHY O. SHEARON and JOSEPH D. ALLEN \\ University of Georgia, Athens, Georgia
}

\begin{abstract}
Three food-deprived male golden hamsters were presented food pellets on a fixed-time 60 -sec schedule with free access to water. Water consumption and number of pellets pouched were recorded for each session of six different experimental phases. The hamsters failed to acquire schedule-induced polydipsia under several environmental manipulations. However, all 3 ham sters acquired schedule-induced pellet pouching, which remained stable across all environmental manipulations.
\end{abstract}

Falk (1961) demonstrated that food-deprived rats drink excessive amounts of water when given food on a discriminable schedule. This phenomenon, subsequently labeled schedule-induced polydipsia (SIP), has been studied in depth and has been shown to be one of a group of schedule-induced behaviors that occur under fooddeprivation conditions (see Falk, 1971, for a review). The generality of SIP has been tested in several species. Among the species that display SIP are: Norway rats (Falk, 1961; McCaffrey, Pavlik, Hoppmann, \& Allen, 1980), chimpanzees (Falk, 1971), humans (Fallon, Allen, \& Butler, 1979), mice (Palfai, Kutscher, \& Symons, 1971), mongolian gerbils (Porter \& Bryant, 1978), guinea pigs (Porter, Sozer, \& Moeschl, 1977), pigeons (Shanab \& Peterson, 1969), and macaques (Allen \& Kenshalo, 1973; Schuster \& Woods, 1966). One species that has failed to show acquisition of SIP is the golden hamster (Wilson \& Spencer, 1975). This article describes a systematic examination of various parameters of the conditioning situation, and the corresponding effects on the behavior of the golden hamster.

\section{METHOD}

\section{Subjects}

The subjects were three golden hamsters, mesocricetus auratus, obtained from the colony at the University of Georgia. The hamsters were approximately 150 days old at the beginning of the study. The subjects were housed in a colony room in individual cages on a 14:10 h light:dark cycle except during daily sessions. Unless otherwise noted, the hamsters were maintained at $80 \%$ of free-feeding weight (FFW) on limited access to Purina Lab Chow with room-temperature water available constantly in the home cage.

\section{Apparatus}

Programming and data collection were accomplished using a Commodore $\mathbf{4 0 3 2}$ microcomputer, a Commodore $\mathbf{4 0 4 0}$ disk drive, and a Commodore 2022 dot-matrix printer located in the room adjacent to the experimental chambers. Test sessions were run in Lehigh Valley

Portions of this research were presented at the 1984 meeting of the Eastern Psychological Association in Baltimore, MD. Requests for reprints may be sent to Joseph D. Allen, Department of Psychology, University of Georgia, Athens, GA 30602. operant-conditioning chambers located within sound-attenuating chambers. Forty-five-milligram standard formula Noyes food pellets were delivered by Gerbrands pellet dispensers. The food magazine was centered on the front panel of the test chambers. Water was available through a stainless-steel drinking tube centered approximately $2 \mathrm{~cm}$ to the right of the food magazine. The drinking tube extended into the operant chamber only far enough to facilitate drinking. White noise $(65 \mathrm{~dB})$ and chamber ventilation fans were on constantly to mask extraneous noise. A 28-V houselight signalled the beginning of each session and remained on until session termination.

\section{Procedure}

Baseline and polydipsia test sessions were $30 \mathrm{~min}$ in length. For baseline sessions (Phase 1) the subjects were placed in the test chamber with 30 pellets already in the magazine. Water intake was recorded for each baseline session and for sessions throughout each subsequent phase. In addition, the hamsters' pouches were manually manipulated to check for uneaten food pellets following each session in all phases. Pellet counting was facilitated because the pellets remained intact and easily countable within the pouches. On four occasions, the subjects were anesthetized and the pellets were removed from their pouches and counted. In the least accurate of these four checks there was $95 \%$ agreement with the manual count.

For all SIP test sessions, pellets were dispensed on a fixed-time 1-min schedule. Subjects were tested 7 days per week and at the same time each day $( \pm 30 \mathrm{~min})$. Following baseline testing, Phase 2 was initiated. In this and all subsequent phases, except the second baseline phase (Phase 5, below), all 3 subjects were run for at least 7 consecutive sessions and until water intake and pellet pouching were stable for at least three consecutive sessions. During Phase 2 we observed that the hamsters had a tendency to fall through the grid floor and thus spent a great deal of time locomoting about the chamber. Therefore, a false floor, ceiling, and back wall made of $1 / 4$-in. hardware cloth were installed in the test chamber, and Phase 3 was initiated. (The resulting measurements of the chamber were $14 \mathrm{~cm} \times 23 \mathrm{~cm} \times 14 \mathrm{~cm}$.) Because a previous study had demonstrated that hamsters will not drink saline solutions (Hoffman, Robinson, \& Magalhaes, 1968), we hypothesized that the ingestion of standard formula Noyes pellets might leave a residual salt or mineral taste in the mouth. Thus, the effects of drinking water with salt in the mouth might mimic the effects of drinking a saline solution. For this reason, in Phase 4, formula "F" 45-mg Noyes pellets were substituted for the standard formula pellets. Since several manipulations had occurred, another baseline, Phase 5, was obtained using the modified operant chamber and the formula "F" pellets. Finally, because some rats did not exhibit SIP until they reached weight reductions closer to $70 \%$ FFW (see Falk, 1971), the hamsters were reduced to $70 \%$ FFW and Phase 6 was initiated. Further reduction in weight was not attempted, as the hamsters exhibited signs of severe deprivation and stress under the $70 \%$ manipulation. 


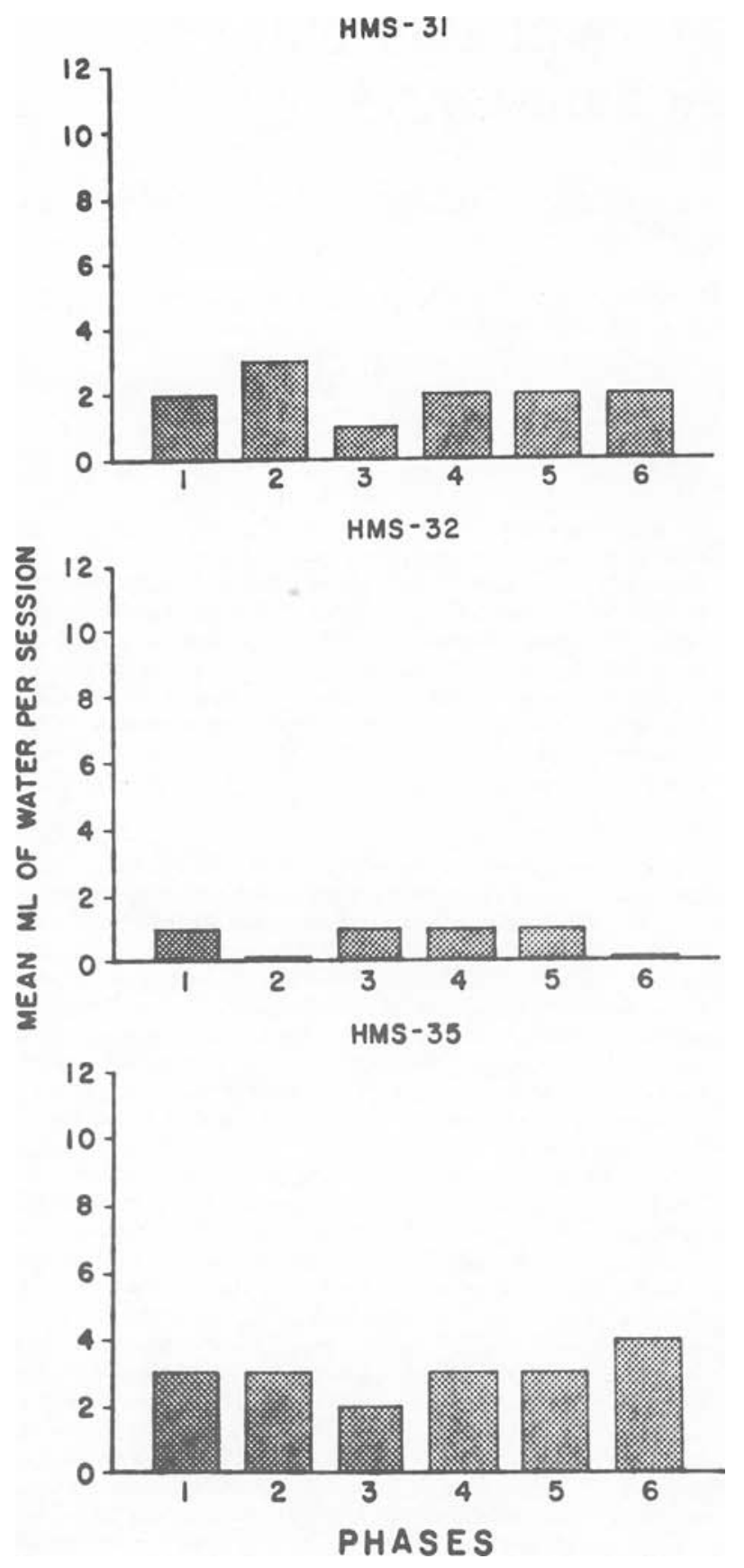

Figure 1. Mean amount of water consumed per session for Phases 1 through 6 for HMS-31, HMS-32, and HMS-35 golden hamsters.

\section{RESULTS}

Figure 1 presents a record of water consumption across all phases for all 3 hamsters. There were no increases above baseline water intake for any of the hamsters under any of the manipulations. Though there was little or no pouching in either baseline, the hamsters did exhibit pellet pouching during all test phases. Figure 2 shows the number of pellets pouched per phase for each subject. The only instance of post-session pellet pouching during a baseline phase occurred on the first day of Phase 5 (recaptured baseline). However, in Phase 2, the first polydipsia test session, all 3 subjects began pouching pellets. Pellet pouching increased regularly throughout the Phase 2 sessions in all 3 hamsters and ultimately became stable (mean $=27$ pellets per session).

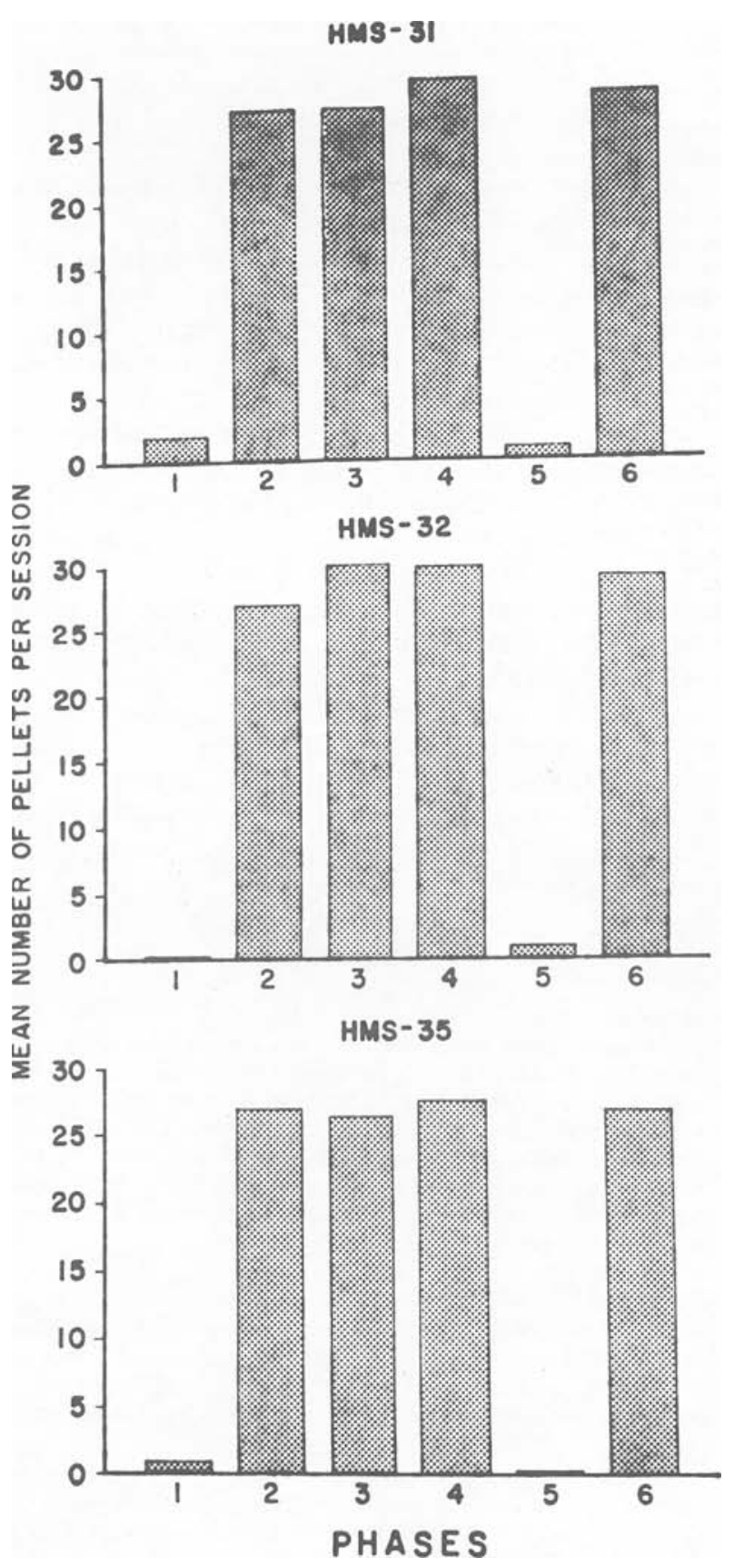

Figure 2. Mean number of pellets pouched per session for Phases 1 through 6 for HMS-31, HMS-32, and HMS-35 golden hamsters. 


\section{DISCUSSION}

There are several plausible explanations for the failure to induce SIP in hamsters. The most logical explanation is that the hamster, being a desert species, has undergone selection pressures that have led to a weaker correlation between behaviors associated with eating and those associated with drinking than has the Norway rat. For example, given proper environmental challenges, hamsters have shown a remarkable ability to control renal function and body-fluid balance (Hoffman, Robinson, \& Magalhaes, 1968). This ability is attributable to certain structural differences known to exist within the kidney of the golden hamster (e.g., an elongated loop of Henle, which allows for greater water reabsorption). Furthermore, the claim that hamsters might obtain schedule-induced polydipsia if the interpellet interval were extended beyond $1 \mathrm{~min}$, as was the case in Mongolian gerbils (Porter \& Bryant, 1978), is mitigated by the results of unpublished work in our laboratory. It has been our experience that hamsters do not drink under these conditions even when the interpellet interval is extended to as long as $120 \mathrm{sec}$.

Inspection of Figure 2 shows that, contrary to the results of earlier studies (Wilson \& Spencer, 1975), hamsters did develop pellet pouching. It might seem plausible that pouching occurred in the baseline condition (in which case it would not be schedule-induced), but pellets were consumed during those sessions. Indeed, observation of behavior during the baseline sessions suggests that the pellets were generally consumed early in the 30-min period. Following pellet consumption, the hamsters usually spent a brief period grooming, and then went to sleep. Further evidence of schedule control of pellet pouching is offered by the systematic increases in pouching that occurred across test sessions. Moreover, occasional observations of the hamsters' behavior revealed highly excited states (indicated by large increases in activity level) that are characteristic of schedule-induced behavior (Falk, 1971). It would seem that the hamsters responded to an environmental stimulation in the test situations that was not present in either of the baseline conditions. The only plausible candidate for this environmental stimulation is the schedule of pellet presentation.

\section{REFERENCES}

Allen, J. D., \& Kenshalo, D. R., JR. (1973). Schedule-induced drinking as a function of interpellet interval and draught size in the Java Macaque. Journal of the Experimental Analysis of Behavior, 30, 139-159.

FALK, J. L. (1961). Production of polydipsia in normal rats by an intermittent food schedule. Science, 133, 195-196.

FALK, J. L. (1971). The nature and determinants of adjunctive behavior. Physiology \& Behavior, 6, 577-588.

Fallon, J. H., Jr., Allen, J. D., \& Butler, J. A. (1979). Assessment of adjunctive behaviors in humans using a stringent control procedure. Physiology \& Behavior, 222, 1089-1092.

Hoffman, R. A., Robinson, P. F., \& Magalhaes, H. (1968). The golden hamster. Ames: Iowa University Press.

McCaffrey, R. J., Pavlik, M. K., Hoppmann, R. A., \& Allen, J. D. (1980). A parametric investigation into the generality of scheduleinduced polydipsia to wild-caught Norway and wild-caught cotton rats. Physiology \& Behavior, 24, 457-461.

Palfia, R., Kutscher, C. L., \& Symons, J. P. (1971). Scheduleinduced polydipsia in the mouse. Physiology \& Behavior, 6, 461-462.

Porter, J. H., \& Bryant, W. E., Jr. (1978). Acquisition of scheduleinduced polydipsia in the Mongolian gerbil. Physiology \& Behavior, 21, 825-827.

Porter, J. H., Sozer, N. N., \& Moeschl, T. P. (1977). Scheduleinduced polydipsia in the guinea pig. Physiology \& Behavior, 19, 573-575.

Shanab, M., \& Peterson, J. L. (1969). Polydipsia in the pigeon. Psychonomic Science, 15, 51-52.

SChUSTER, C. R., \& WoODS, J. H. (1966). Schedule-induced polydipsia in the rhesus monkey. Psychological Reports, 19, 823-825.

WILSON, S., \& SPENCER, W. B. (1975). Schedule-induced polydipsia: Species limitations. Psychological Reports, 36, 863-866.

(Manuscript received November 14, 1988.) 